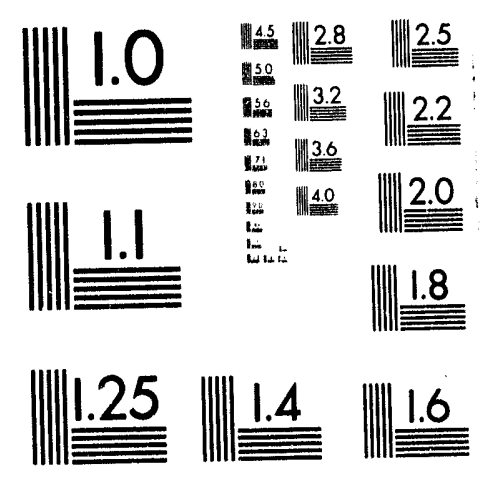



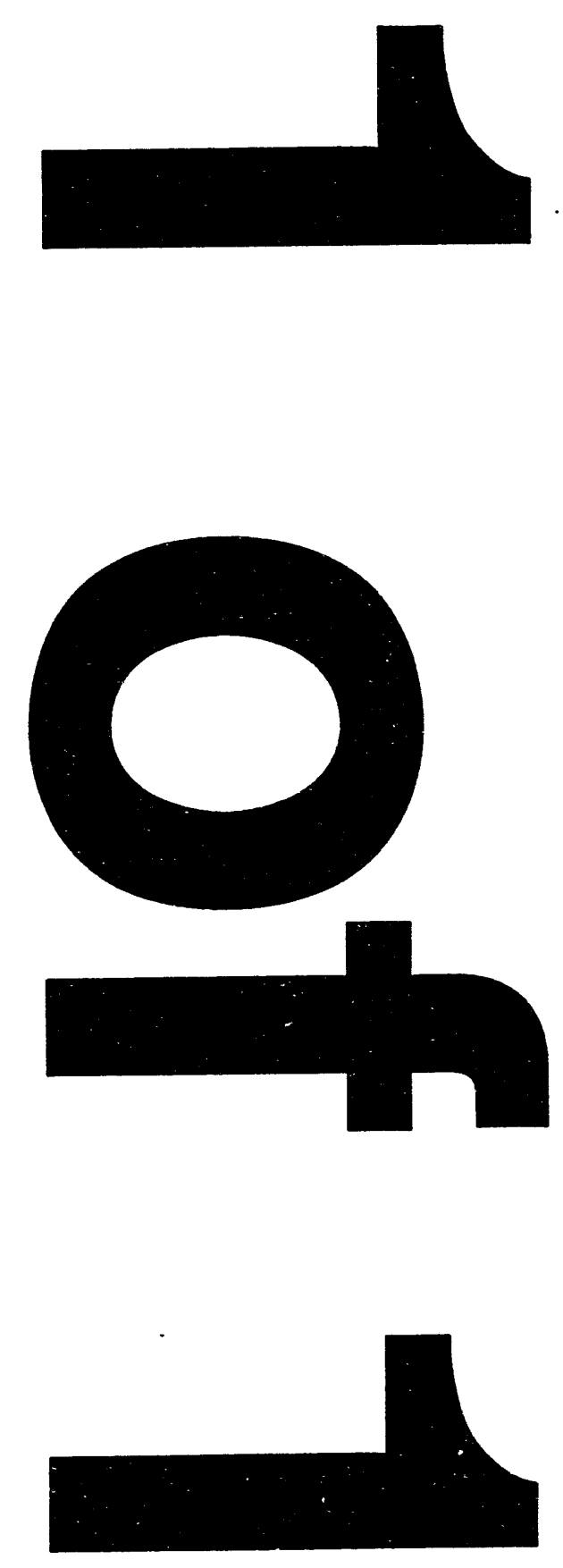
UCRL-JC-115625

PREPRINT

\section{Femtosecond Probe-Probe Transmission Studies of LT-Grown GaAs Near the Band Edge}

H. B. Radousky, A. F. Bello, D. J. Erskine, L. N. Dinh, M. J. Bennahmias, M. D. Perry, T. R. Ditmire and R. P. Mariella, Jr.

This paper was prepared for submittal to the proceedings of the MRS Materials Research Society 1994 Spring Meeting

April 4-8, 1994

San Francisco, CA

December 1993

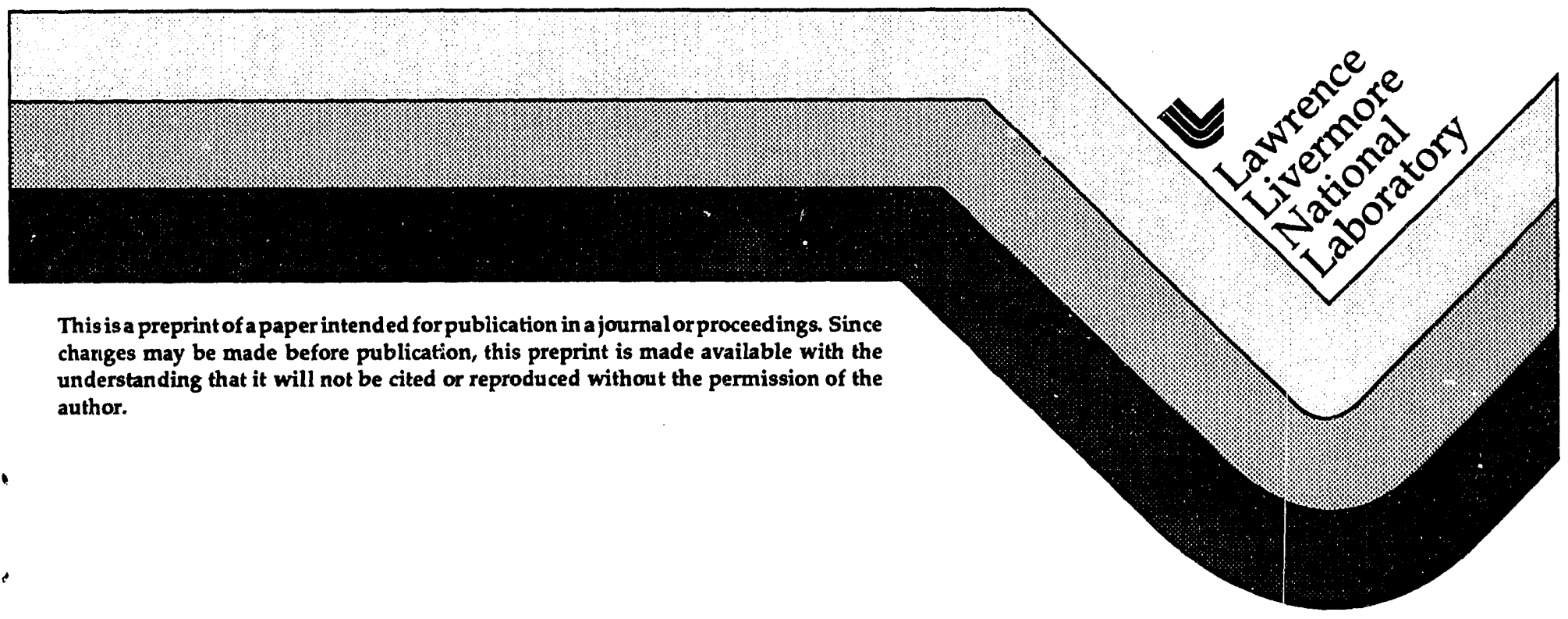




\section{Disclaimer}

This document was prepared as an account of work sponsored by an agency of the United States Government. Neither the United States Government nor the University of Callfornia nor any of their employees, makes any warranty, express or implied, or assumes any legal liability or responsibility for the accuracy, completeness, or usefulness of any information, apparatus, product, or process disclosed, or represents that its use would not infringe privately owned rights. Reference herein to any specific commercial products, process, or service by trade name, trademark, manufacturer, or otherwise, does not necessarily constitute or imply its endorsement, recommendation, or favoring by the United States Government or the University of California. The views and opinions of authors expressed herein do not necessarily state or reflect those of the United States Government or the University of California, and shall not be used for advertising or product endorsement purposes. 


\title{
FEMTOSECOND PROBE-PROBE TRANSMISSION STUDIES OF LT-GROWN GaAs NEAR THE BAND EDGE,
}

\author{
H. B. RADOUSKY A. F. BELLO, D. J. ERSKINE, L. N. DINH, M. J. BENNAHMIAS, \\ M. D. PERRY, T. R. DITMIRE AND R. P. MARIELLA JR., \\ Lawrence Livermore National Laboratory, Livermore, CA 94550.
}

\begin{abstract}
We have studied the near-edge optical response of a LT-grown GaAs sample which was deposited at $300^{\circ} \mathrm{C}$ on a Si substrate, and then annealed at $600^{\circ} \mathrm{C}$. The $\mathrm{Si}$ was etched away to leave a 1 micron free standing GaAs film. Femtosecond transmission measurements were made using an equal pulse technique at four wavelengths between 825 and $870 \mathrm{~nm}$. For each wavelength we observe both a multipicosecond relaxation time, as well as a shorter relaxation time which is less than 100 femtoseconds.
\end{abstract}

\section{INTRODUCTION}

Low temperature grown $\mathrm{GaAs} s^{1-2}$ has been of considerable interest in the last few years do to the sub-picosecond recombination times. This increased interest is do both to the possibilities of utilizing the faster response times in electronic devices, ${ }^{3-8}$ as well as understanding the basic physics underlying the faster response. 9 In many cases, the faster times are attributed to the presence of As impurities in the annealed samples, though fast time times have also been observed in amorphous, unannealed samples. 10 In this paper we report femtosecond transmission spectra on a free standing LT-GaAs film initially grown on a silicon substrate.

\section{EXPERIMENTAL DETAILS}

Solid state lasers with short pulses comparable to CPM dye lasers have been recently developed based on Ti-Sapphire.11-12 In addition to the simplicity of use compared to dye lasers, they provide orders of magnitude higher average power and are tunable over a broad range of frequencies. The laser used in these experiments can provide sub-100 fs pulses with $600 \mathrm{~mW}$ average power and is tunable in the current 
configuration from 800 to $900 \mathrm{~nm}$. This wavelength regime brackets the GaAs band gap at $870 \mathrm{~nm}$.

When focused in a GaAs sample, these optical pulses can promote electrons from the valence band to the conduction band, non-destructively creating highly nonequilibrium conditions. In our experiment, we have utilized a probe-probe version ${ }^{13-14}$ of the standard pump-probe technique. The beam is split into two equal parts, with one pulse delayed with respect to the second. The reflectivity or transmitivity is then measured as a function of the delay time. The second pulse probes the dynamical process at a given time delay relative to the first. In this way, the time averaged optical propertics map out, as a function of delay, the relaxation over the first several picoseconds following excitation. The symmetrical nature of the probe-probe technique

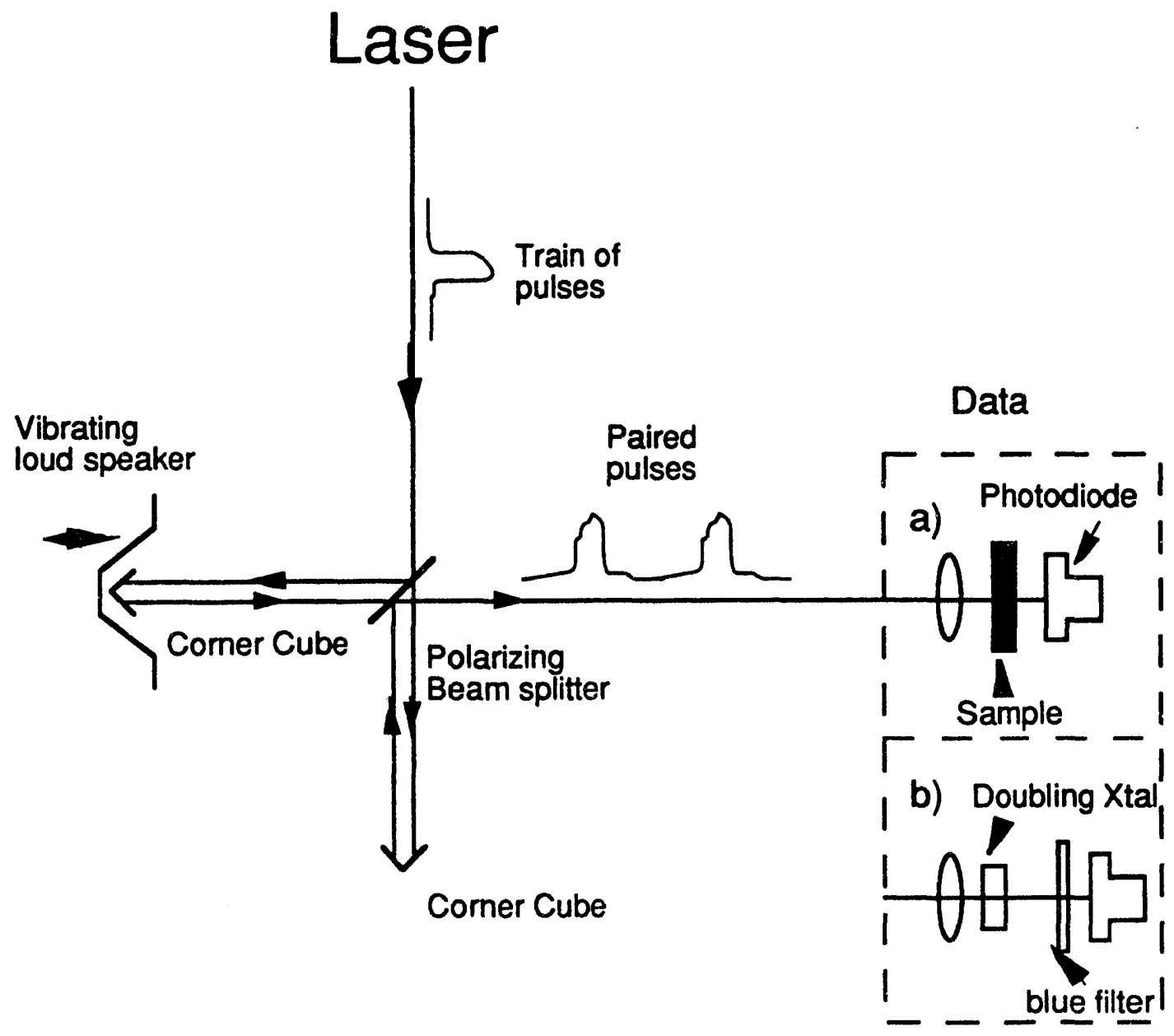

Autocorrelation

Figure 1 - Experimental set-up for the equal-pulse transmission measurements. 
facilitates resolving relaxation times that are comparable or shorter than the pulse width. As a separate feature of the setup, a vibrating speaker is used to sweep through the relevant delays between the pulses many times each second. This allows for both ease in finding the signal, as well as faster collection times. It is analogous to taking a photoluminescence spectra using a scanning spectrometer and a photomultiplier tube, as opposed to using a multichannel analyzer. Both the pump-probe and probe-probe configurations can be used with the vibrating speaker. The diagram for the experimental setup is illustrated in Figure 1.

\section{FILM GROWTH AND CHARACTERIZATION}

The GaAs films were grown by MBE on $\mathrm{Si}$ substrates. The substrate temperature was $300^{\circ} \mathrm{C}$. Following growth, the film was annealed for 10 minutes at $600{ }^{\circ} \mathrm{C}$. The advantage of growth on $\mathrm{Si}$ is that this substrate is easy to etch away, leaving a free standing GaAs film, which was 3 microns thick. This thickness corresponds to one optical absorption length at $825 \mathrm{~nm}$, which is the appropriate dimensions for this experiment. The sample was masked prior to etching away the substrate, so that a series of 3 micron, free standing GaAs windows was created.

The GaAs film was characterized by photoluminescence, which is shown below in Fig. 2. The film was excited by green $514 \mathrm{~nm}$ light from an Ar ion laser. The peak of the spectra is at $870 \mathrm{~nm}$, corresponding to a gap energy of $1.43 \mathrm{eV}$. This indicates that the GaAs gap is essentially unchanged from bulk GaAs. ${ }^{15}$ It is expected that defects are introduced by the low temperature growth.7-10 The photoluminescence clearly shows the presence of defects both from the broadening of the luminescence spectra and by the appearance of a second peak near $900 \mathrm{~nm}$. This would imply that we should see optical absorption even if the excitation energy is equal to or slightly greater than the gap energy. This is indeed what is observed in this sample.

\section{RESULTS AND DISCUSSION}

Prior to the availability of Ti-Sapphire lasers, the femtosecond studies of GaAs have relied on laser pump pulses near $2 \mathrm{eV}$ in energy from CPM dye lasers. 13-14,16-17 The new laser sources are now providing the opportunity to study the fast optical response of GaAs using pump beams centered near the band gap energy of $1.43 \mathrm{eV} .18$ This is in contrast to studies which use $2 \mathrm{eV}$ pump beams and probe beams with energies close to the band edge. ${ }^{16-17}$ 


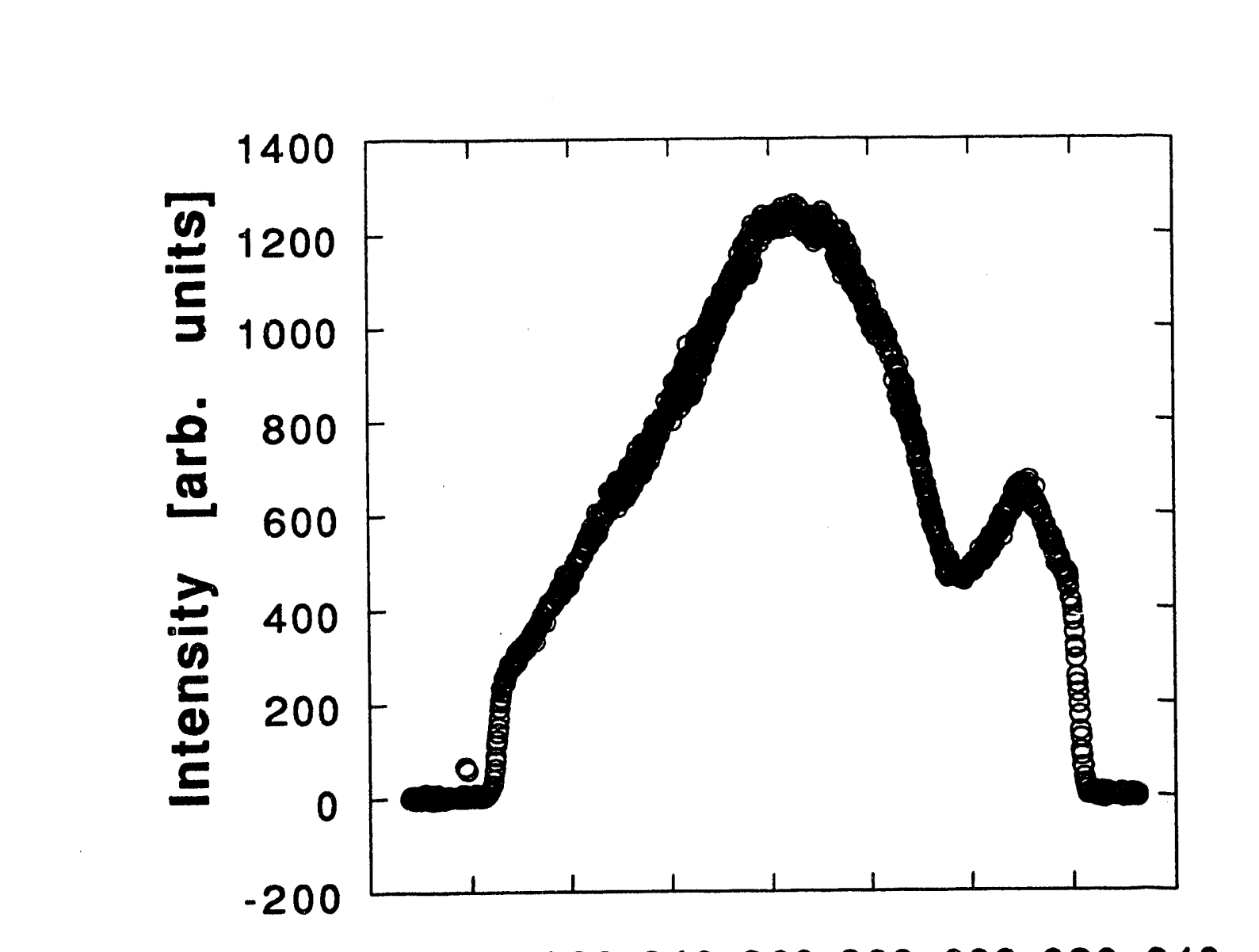




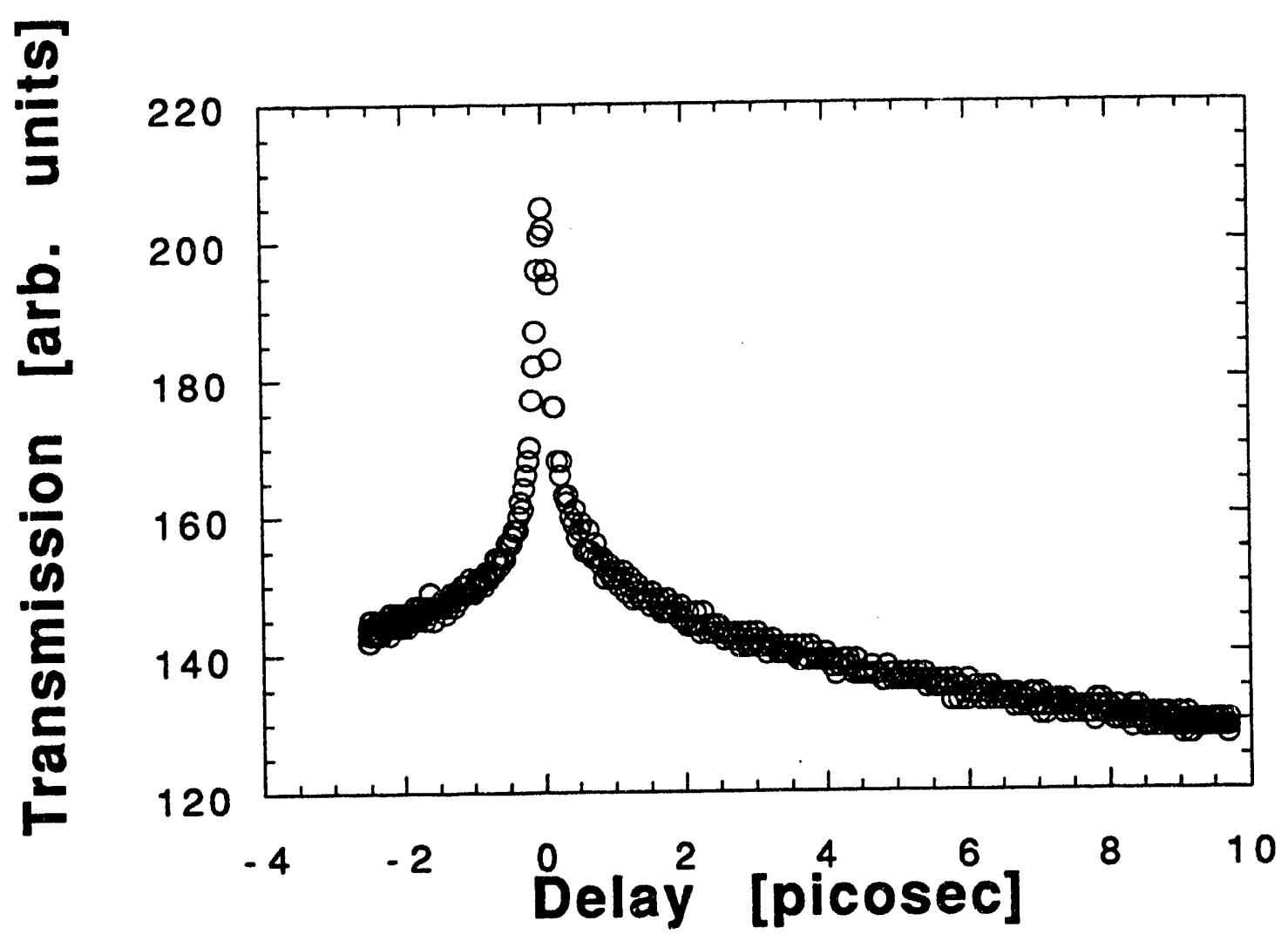

Fig. 3 TCP for LT-grown GaAs at $870 \mathrm{~nm}$.

gives results similar to growth on other substrates, and provides a convenient means to create free standing films and windows.

\section{ACKNOWLEDGMENTS}

This work was performed at Lawrence Livermore National Laboratory under the auspices of the U.S. Department of Energy under contract number W-7405-ENG-48. 


\section{REFERENCES}

1F. W. Smith, A. R. Calawa, C. L. Chen, M. J. Manfra and L. J. Mahoney, IEEE Electron Device Lett. 9,77 (1988).

2F. W. Smith, H. Q. Le, V. Diadiuk, M. A. Hollis, A. R Calawa, S. Gupta, M. Frankel, D. R. Dykaar, G. A. Mourou, and T. Y. Hsiang, Appl. Phys. Lett. 54,890 (1989).

${ }^{3}$ F. W. Smith, H. Q. Le, M. Frankel, V. Diadiuk, M. A. Hollis, D. R. Dykaar, G. A. Mourou and A. R. Calawa, OSA Proceedings on Picosecond Electronis and Optoelectronics, ed. T. C. L. Gerhard Sollner and D. M. Bloom, 4,176 (1989).

4 S. Gupta, S. L. Williamson, J. F. Whitaker, Y. Chen and F. W. Smith, Laser Focus World, July, 1992.

5S. Gupta, M. Y. Frankel, J. A. Valdmanis, J. F. Whitaker, G. A. Mourou, F. W. Smith and A. R. Calawa, Appl. Phys. Lett. 59, 3276 (1991).

${ }^{6}$ S. Gupta, J. F. Whitaker, S. L. Willaimson, G. A. Mourou, L. Lester, K. C. Hwang, P. Ho, J. Mazurowski and J. M. Ballingall, J. Electronic Material, in press.

${ }^{7}$ H. H. Wang, J. F. Whitiker, A. Chin, J. Maxurowski and J. M. Ballingall, J. Electronic Materials, in press.L. F. Lester, K. C. Hwang, P. Ho, J. Mazurowski, J. M. Ballingall, J. Sutliff, S. Gupta, J. Whitaker and S. L. Willaimson, IEEE Photonics Tech. Lett. (in press).

${ }^{8}$ M. Y. Frankel, J. F. Whitiker, G. A. Mourou, F. W. Smith and A. R. Calawa, IEEE Transaction on Electronic Devices, 37 (1990).

${ }^{9}$ X. Q. Zhou, H. M. van Driel, W. W. Ruhle, Z. Gogolak and K. Ploog, Appl. Phys. Lett 61,3020 (1992).

${ }^{10}$ A. C. Warren, J. M. Woodall, J. L. Freeouf, D. Grischkowsky, M. R. Mellolch and N. Otsuka, Appl. Phys. Lett. 57,1331 (1990).

11W. S. Pelouch, P. E. Powers and C. L. Tang, Optics Letters 17, 1070 (1992).

12B. Proctor and F. Wise, Appl. Phys, Lett. 62, 470 (1993).

${ }^{13}$ C. L. Tang and D. J. Erskine, Phys. Rev. Lett. 51, 840, (1983).

${ }_{14}$ A. J. Taylor, D. J. Erskine and C. L. Tang, Appl. Physics Letters, 43,989 (1983).

15I. L. Spain, M. S. Skolnick, G. W. Smith, M. K. Saker and C. R. Whitehouse, Phys. Rev. B 43,14091 (1991) and references therein.

16C. J. Stanton, D. W. Bailey adn K. Hess, Phys. Rev. Lett. 65, 231 (1990). and references therein.

17T. Gong, W. L. Nighan and P. M. Fauchet, Appl. Phys. Lett. 57, 2713 (1990). and references therein.

18J. F. Whitaker, Materials Science and Engineering B (in press) and reference therein.

${ }^{19}$ A. F. Bello, D. J. Erskine, H. B. Radousky, L. N. Dinh, M. J. Bennahmias,

M. D. Perry, T. R. Ditmire AND R. P. Mariella Jr., unpublished. 


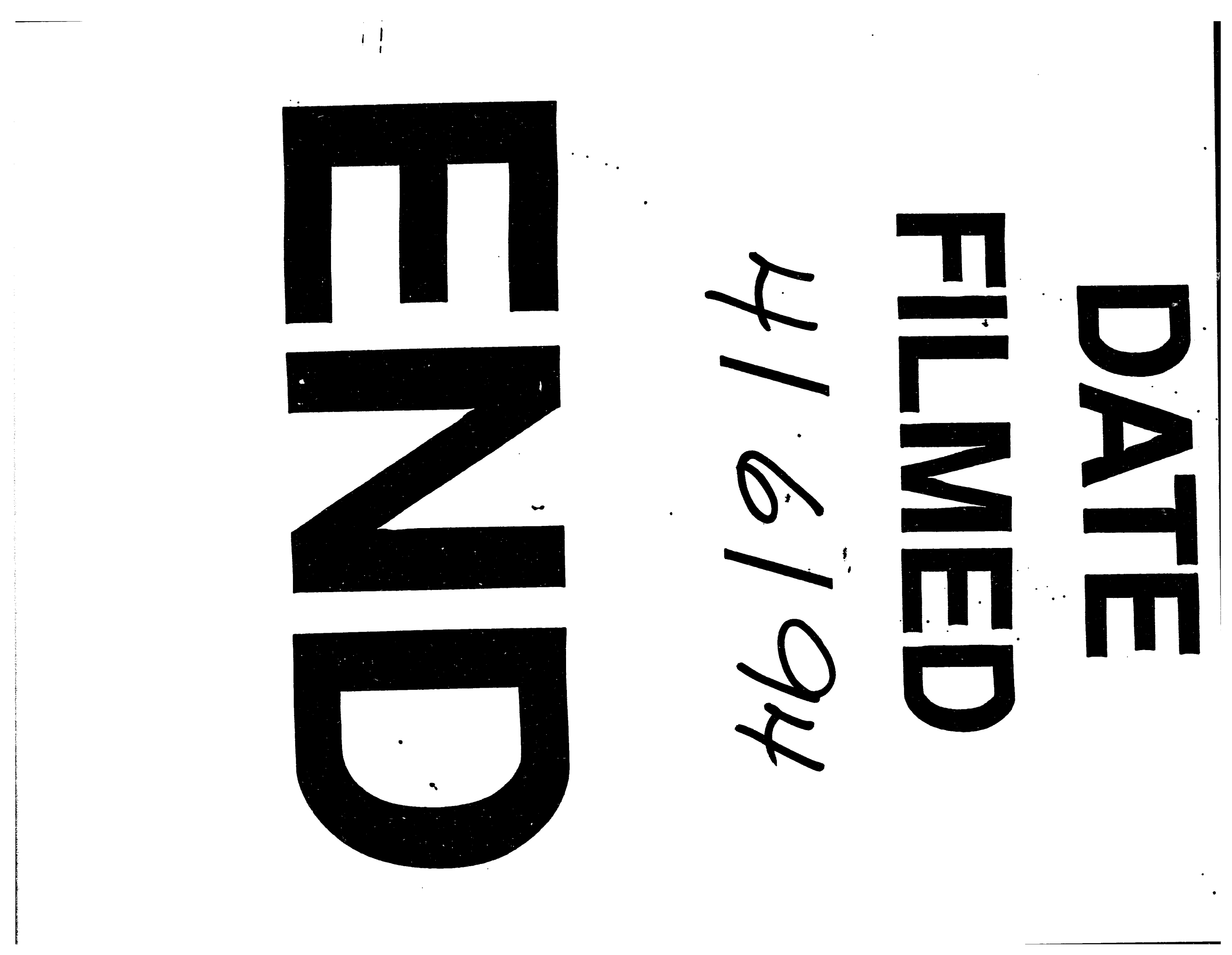


